\title{
Growing a growth mindset: characterizing how and why undergraduate students' mindsets change
}

\author{
Lisa B. Limeri ${ }^{1 *} \mathbb{D}$, Nathan T. Carter ${ }^{2}$, Jun Choe ${ }^{1}$, Hannah G. Harper ${ }^{1}$, Hannah R. Martin ${ }^{3}$, Annaleigh Benton ${ }^{4}$ and \\ Erin L. Dolan ${ }^{1}$
}

\begin{abstract}
Background: The extent to which students view their intelligence as improvable (i.e., their "mindset") influences students' thoughts, behaviors, and ultimately their academic success. Thus, understanding the development of students' mindsets is of great interest to education scholars working to understand and promote student success. Recent evidence suggests that students' mindsets continue to develop and change during their first year of college. We built on this work by characterizing how mindsets change and identifying the factors that may be influencing this change among upper-level STEM students. We surveyed 875 students in an organic chemistry course at four points throughout the semester and interviewed a subset of students about their mindsets and academic experiences.

Results: Latent growth modeling revealed that students tended to shift towards viewing intelligence as a stable trait (i.e., shifted towards a stronger fixed mindset and a weaker growth mindset). This trend was particularly strong for students who persistently struggled in the course. From qualitative analysis of students' written survey responses and interview transcripts, we determined that students attribute their beliefs about intelligence to five factors: academic experiences, observing peers, deducing logically, taking societal cues, and formal learning.

Conclusions: Extensive prior research has focused on the influence of mindset on academic performance. Our results corroborate this relationship and further suggest that academic performance influences students' mindsets. Thus, our results imply that mindset and academic performance constitute a positive feedback loop. Additionally, we identified factors that influence undergraduates' mindset beliefs, which could be leveraged by researchers and practitioners to design more persuasive and effective mindset interventions to promote student success.
\end{abstract}

Keywords: Growth mindset, Fixed mindset, Implicit theories of intelligence, Mindset development

\section{Introduction}

Students' academic success is influenced not only by their cognitive abilities and content knowledge, but also by non-cognitive factors, such as their beliefs, attitudes, and values. One influential non-cognitive factor is students' beliefs about the degree to which intelligence is a stable trait, termed "mindset" (Dweck, 1999). Students who believe that intelligence is a stable, unchangeable trait are

\footnotetext{
*Correspondence: lisa.limeri@uga.edu

'Department of Biochemistry \& Molecular Biology, University of Georgia,

B206.2 Life Sciences Building, 30602 Athens, GA, USA

Full list of author information is available at the end of the article
}

described as holding a "fixed mindset" and are likely to interpret struggle or failure as an indication that they are not intellectually capable of succeeding (Dweck, 1999). Thus, students with a fixed mindset tend to avoid challenges, quit when they encounter challenge, and ultimately achieve less academic success (Dweck, 1999; Smiley, Buttitta, Chung, Dubon, \& Chang, 2016). Conversely, students who believe that intelligence is a changeable trait that they can improve with effort and guidance are described as holding a "growth mindset." These students are more likely to take on challenging tasks and persist through challenges by trying new strategies or increasing effort, 
ultimately achieving greater academic success (Dweck, 1999; Smiley et al., 2016).

Students' mindsets are influential because they affect a variety of other non-cognitive factors, such as the types of goals students set (Dweck \& Leggett, 1988; Hoyert \& O'Dell, 2008), how students attribute their successes and struggles (Dweck, 1999; Smiley et al., 2016), and how they cope with challenges they encounter (Heine et al., 2001). Given the far-reaching influence of mindsets, it is important to understand how and why students' mindsets develop and change over time.

Students' mindsets themselves are malleable and appear to change over time. Researchers have investigated how they can encourage students to develop a growth mindset through conducting "mindset interventions," which are brief activities or tasks that attempt to sway students toward a growth mindset. Successful mindset interventions have boosted students' grades and persistence in STEM (Yeager et al., 2019; Yeager \& Walton, 2011) and reduced or eliminated racial achievement gaps (Aronson, Fried, \& Good, 2002). However, there has been considerable variability in the success of intervention attempts (e.g., Orosz, Péter-Szarka, Bőthe, Tóth-Király, \& Berger, 2017). In fact, a recent meta-analysis of mindset interventions revealed that, among studies conducted with undergraduate students (13 independent samples; $N=7,871$ ), there was no average effect of mindset interventions $(d=0.08,95 \% \mathrm{CI}$ $=[-0.02,0.17], p=0.123$; Sisk, Burgoyne, Sun, Butler, \& Macnamara, 2018).

The success of mindset interventions hinges on their ability to persuade participants to shift their mindsets. Yet, Sisk and colleagues' meta-analysis (Sisk et al., 2018) revealed that nearly half $(46 \%)$ of mindset interventions that measured mindsets before and after the intervention (i.e., manipulation check) failed to shift students' mindsets. This implies that some mindset interventions may fail to produce measurable improvements because they were not effective in convincing students to adopt growth mindset beliefs. Mindset interventions could potentially be made more persuasive if their messaging was informed by data on how students form and change their beliefs about intelligence throughout their life. Thus, the goal of our study is to gain deeper insight into how and why undergraduate students' mindsets change.

\section{Change in mindsets over time}

There is evidence that students' mindsets change over time in the absence of an intervention (Kinlaw \& KurtzCostes, 2003). A comprehensive review of studies investigating how children's ideas about intelligence develop as they mature throughout primary and secondary school reported that this literature has yielded mixed results (Kinlaw \& Kurtz-Costes, 2003). For example, Gunderson and colleagues (2017) conducted a cross- sectional study that found that students in middle school held stronger fixed mindsets about both math and reading/writing than both younger students in elementary school and older students in high school and college. Pomerantz and Saxon's (2001) longitudinal study of students from fourth through sixth grade revealed that, as they aged, students increasingly viewed intelligence as a stable trait. Conversely, another longitudinal study of fifth- and sixth-grade students in Greece showed that growth beliefs about intelligence tended to get stronger over one year (Gonida, Kiosseoglou, \& Leondari, 2006).

There has been comparatively less work on mindset development in undergraduate students. Two studies found no evidence of mindset change during college. Gunderson and colleagues' (2017) cross-sectional study found that first- and second-year undergraduate students' mindsets about math and reading/writing did not differ from high school students'. Similarly, a longitudinal study of second- through fourth-year undergraduate students showed no change in mean fixed mindset scores on a domain-general measure of mindset (Robins \& Pals, 2002). In contrast, a handful of recent studies have shown that undergraduate students do change their mindsets over their first year (Dai \& Cromley, 2014; Flanigan, Peteranetz, Shell, \& Soh, 2017; Scott \& Ghinea, 2014; Shively \& Ryan, 2013). A series of pre/post studies have shown that students tend to decrease in growth mindsets and increase in fixed mindsets throughout introductory undergraduate STEM courses, specifically in biology (Dai \& Cromley, 2014), computer science (Flanigan et al., 2017; Scott \& Ghinea, 2014), and math (Shively \& Ryan, 2013). For example, Dai and Cromley (2014) measured the mindsets of 335 undergraduate students before and after year-long, two-course introductory biology series and found that students tended to report increased fixed mindset and decreased growth mindset. Considered together, existing research agrees that introductory STEM students tend to shift towards fixed mindsets, but the two studies that have included mid- and upper-level undergraduates have failed to find change in mindsets over time. Thus, more work is needed to understand the dynamics of undergraduate students' mindsets past their first year of studies.

\section{Factors influencing students' mindsets}

These studies suggest that students' mindsets develop and change throughout their lives, including in college. However, little work has been done to examine the factors that influence mindset change. Dweck and colleagues have investigated factors that influence how young students form their mindsets (Dweck, 1999; Kamins \& Dweck, 1999; Mueller \& Dweck, 1998). Their work demonstrates that how educators and parents praise children communicates implicit messages about 
the nature of intelligence. Specifically, praising a students' attributes (e.g., their intelligence) implies that success is the result of their innate traits and encourages a fixed mindset whereas praising students' process (e.g., their effort) implies that success is the result of their behaviors and encourages a growth mindset (Dweck, 1999; Kamins \& Dweck, 1999). Gonida and colleagues (2006) concluded that middle school students' academic performance predicted their mindset beliefs. They conducted a year-long longitudinal study and tested a set of three alternative models to establish causality. They found that students who experienced greater academic success had stronger growth mindsets in the subsequent year. These results indicate that students' academic experiences may influence their mindset beliefs. However, this study was conducted with Greek middle school students, and it remains unclear whether these results could generalize to students at different ages and in different cultural contexts.

Even less is known about the factors that influence mindsets of undergraduate students. Flanigan and colleagues (2017) examined how students' academic motivation and engagement may influence the development of their mindset beliefs. They grouped first-year undergraduate students into "motivated self-regulated engagement profiles" based on a suite of motivational, selfregulation, affective, and strategic engagement variables. They found that students in different groups changed their mindsets to varying degrees throughout an introductory computer science course. For example, students in the "helpless" profile shifted towards a fixed mindset more strongly than students in other profiles (Flanigan et al., 2017). This study suggests that students' motivational traits are one factor influencing their mindsets, but more work is needed to explain the mechanism of this effect and to identify any additional factors.

\section{Research goals}

It is clear that students' mindsets change over time and that undergraduate students' mindsets are still changing in the absence of an intervention. However, many questions about mindset development remain open. We have a limited understanding of the dynamics of undergraduates' mindsets after their first year because prior studies of undergraduate students' mindsets have targeted introductory courses. Furthermore, these studies have yielded little insight into the factors that influence mindset change. Here, we begin to address these knowledge gaps guided by two research goals: (1) to characterize how undergraduates' mindsets change in a mid-level, challenging STEM course and (2) to identify and describe factors that could be influencing undergraduate students' mindsets.

\section{Methods}

We adopted an exploratory and descriptive approach because there has been minimal empirical work done on mindset change in mid-level undergraduate students. To investigate change in mindsets over time, we collected data longitudinally throughout the semester. We utilized a concurrent nested mixed-methods approach involving closed-response and constructed-response survey questions as well as interviews with a subset of participants because our two research goals needed to be addressed by different types of data (Warfa, 2016). Specifically, we relied primarily on quantitative data to characterize how students' mindsets changed over time and primarily qualitative data to identify and characterize the factors that could be influencing students' mindsets. We surveyed students about their mindsets four times throughout the semester in a challenging mid-level STEM course. We also surveyed students about their struggles in the course. We conducted latent growth modeling to investigate how mindsets changed over the semester and how students' perceived experiences of academic failure or success were related to their mindsets. We also conducted conventional content analysis of constructed response survey questions and interviews to identify factors that could be influencing undergraduate students' mindsets (Hsieh \& Shannon, 2005). This data collection occurred as part of a larger exploratory study about undergraduate students' mindsets and coping with academic challenge. This study was reviewed and determined to be exempt by the University of Georgia Institutional Review Board (STUDY00005634).

\section{Participants}

Our study participants were enrolled in a challenging mid-level STEM course (Organic Chemistry II) at a single large southeastern public university with very high research activity. We recruited participants from Organic Chemistry II because it is a required course for many professional schools and STEM majors. Further, because we were interested in exploring how students cope with struggle and the relationship between their academic performance and mindsets, we wanted to target a particularly challenging course, and Organic Chemistry has a national and local reputation for being a challenging STEM course.

Participants were compensated with a small amount of extra credit for completing the surveys. We surveyed students in the spring 2018 semester and repeated the quantitative data collection in the spring 2019 semester to increase the sample size. The course enrolled around 500 students each semester (510 in 2018, 500 in 2019), of which 875 students participated in the study by completing at least one survey (411 in 2018, 464 in 2019). The study sample consisted of mostly second-year 
students (63\%), about half of whom were white $(56 \%)$ and majoring in the life sciences (56\%; Table 1). We used students' constructed survey responses to select 20 participants to interview for this study from the 2018 cohort (see Additional file 1, Section 2 for further details about this selection process). We purposely selected participants who expressed diverse perspectives in their survey responses, who reported a mix of growth and fixed mindsets, and who were diverse in their personal characteristics (Table 1).

\section{Data collection}

\section{Survey administration}

Each survey consisted of two versions of the mindset scale (Dweck, 1999), one focused on chemistry intelligence and the other on general intelligence, as well as additional closed-response and constructed-response questions (Survey Questions in Additional file 1, Section $1)$. Students were surveyed four times throughout the semester. Survey timing was coordinated in relationship to course milestones: the first survey occurred in the second week of class, the second survey just after the first exam scores were returned, the third survey around the course withdrawal deadline, and the last survey at the end of the semester between the end of classes and the final exam. The first three surveys were spaced approximately 2 weeks apart, but the fourth survey was administered approximately 4 weeks after the third survey. The uneven spacing between surveys is accounted for in the latent growth models by the specification of the loadings on the slope variable (see "Latent_Growth_Models.R" file for $R$ code).

\section{Mindset scale}

The mindset scale consists of eight items, which we tailored to the chemistry course context: four measuring a growth mindset (e.g., "No matter who you are, you can significantly change your chemistry intelligence level") and four measuring a fixed mindset (e.g., "Your chemistry intelligence is something about you that you can't change very much") (Dweck, 1999). We chose to use "chemistry intelligence" because there is evidence that responses to the mindset scale are more accurate and predictive of academic outcomes when the questions are context-specific to the course being studied (Shively \& Ryan, 2013). However, it is important to note that this

Table 1 Demographic information of study participants

\begin{tabular}{|c|c|c|c|}
\hline & & Survey respondents $(\boldsymbol{n}=875)$ & Interview participants $(\boldsymbol{n}=20)$ \\
\hline \multirow[t]{3}{*}{ Gender } & Female & $503(57 \%)$ & 15 \\
\hline & Male & $281(32 \%)$ & 5 \\
\hline & Other & $1(<1 \%)$ & 0 \\
\hline \multirow[t]{3}{*}{ Major } & Life sciences & $491(56 \%)$ & 14 \\
\hline & Other STEM & $279(32 \%)$ & 5 \\
\hline & Non-STEM & $11(1 \%)$ & 1 \\
\hline \multirow[t]{4}{*}{ College year } & First-year & $9(1 \%)$ & 1 \\
\hline & Second-year & $548(63 \%)$ & 15 \\
\hline & Third-year & $150(17 \%)$ & 2 \\
\hline & Fourth-year & $78(9 \%)$ & 2 \\
\hline \multirow[t]{8}{*}{ Race / ethnicity } & White & $492(56 \%)$ & 12 \\
\hline & South Asian & $125(14 \%)$ & 4 \\
\hline & African American/Black & $87(10 \%)$ & 3 \\
\hline & East Asian & $68(8 \%)$ & 0 \\
\hline & Latin $(x) /$ Hispanic & $38(4 \%)$ & 1 \\
\hline & Middle Eastern/North African & $21(2 \%)$ & 1 \\
\hline & Native American or Alaskan Native & $5(1 \%)$ & 1 \\
\hline & Native Hawaiian or other Pacific Islander & $3(<1 \%)$ & 0 \\
\hline \multirow[t]{2}{*}{ Parents' education } & Continuing generation & $658(75 \%)$ & 15 \\
\hline & First generation & $136(15 \%)$ & 5 \\
\hline
\end{tabular}

Counts may not sum to $100 \%$ because some participants chose not to respond and participants were able to select more than one racial/ethnic identity. First generation indicates that none of the students' parents/guardians earned a bachelor's degree or higher. Life sciences indicates that students have at least one major in life sciences, including animal sciences and excluding pharmaceutical sciences. Other STEM majors are students who have at least one major in a non-life sciences STEM field as defined by the National Science Foundation, which includes the social sciences. Participants who identified with more than one race/ ethnicity are counted in both groups. South Asian includes individuals identifying as Filipino, Asian Indian, Vietnamese, and other South Asian. East Asian includes individuals identifying as Chinese, Korean, and Japanese 
approach may limit the extent to which these results can be generalized beyond the context of chemistry. Participants responded to these items using a 7-point scale of agreement (i.e., 1 = "strongly disagree"; 7 = "strongly agree"). Scores for growth mindset and fixed mindset were calculated by averaging participants' responses to the four growth and fixed items, respectively. Average scores were only calculated if the participant responded to all four items. If they selected "prefer not to respond" to any of the items, the average score was not calculated and the data were considered missing.

We screened out participants who responded to the survey questions with insufficient effort (DeSimone, Harms, \& DeSimone, 2015). Specifically, we included a directed-response item in each survey that read, "This is a control question. Please select [directed response, e.g., 'disagree'] as your response to this item." We discarded mindset scale responses from participants who did not select the directed response. Additionally, we discarded "long string" responses where participants selected the same extreme response for over half of the mindset scale ( 5 or more items out of 8 total). The items representing growth mindset and fixed mindset are interspersed throughout the scale, making it unlikely that participants would "agree," "strongly agree," "disagree," or "strongly disagree" with five items in a row. We kept data from participants who selected a long string of "somewhat agree," "neither agree nor disagree," or "somewhat disagree" because participants could reasonably have no opinion or a weak opinion about these items. Relatively few responses were removed due to either the directed response questions or long string responses (fewer than 15 on any survey). Thus, insufficient effort screening is unlikely to substantially affect the analyses and conclusions of this study.

We calculated and modeled growth mindset and fixed mindset as separate constructs rather than reverse-coding growth items to create a single score. Previous studies have found that growth and fixed mindsets are separate constructs, although they are highly negatively related; it is inappropriate to combine responses on the scales as if they were a single construct (Cook, Castillo, Gas, \& Artino, 2017). Confirmatory factor analyses of our data confirm that the two-factor structure is a better fit to the data than a one-factor structure (confirmatory factor analyses in Additional file 1, Section 4). For all analyses, we estimated separate models for growth and fixed mindsets because they were highly negatively correlated $(r=-0.73$ in our data) and we encountered multicollinearity issues when they were included in the same models.

\section{Students' perceptions of academic performance}

Extensive prior research suggests that mindsets should influence students' academic success (Dweck, 1999;
Yeager et al., 2019). To model the relationship between students' mindsets and academic experiences, we asked students about their perceived level of success or failure in the course; we termed this variable "failure perception." We chose to operationalize students' academic performance with their perceptions of their performance rather than an objective measure of their actual performance (such as course grades) because students' subjective perceptions of their academic performance should be more directly relevant to understanding their lived experiences than objective measures of their actual performance. For example, some students may see an average grade (e.g., "C") as failing to meet their high standards whereas other students may see receiving a passing grade as a success.

We operationalized failure perception using two "Yes/ No" questions on the fourth and final survey of each semester. First, students were asked, "Did you encounter struggle in Organic Chemistry II this semester?" Of the 659 students who answered these questions, only 88 students indicated that they did not struggle; these students were categorized as "never struggled." Students who answered "Yes" were then asked, "Were you able to overcome struggle that you encountered?" The majority of students (462/659) indicated that they overcame the struggle they encountered by answering "Yes"; these students were categorized as "overcame struggle." About 16\% of students (109/659) indicated that they encountered a struggle that they did not overcome by answering "No"; these students were categorized as "continued struggle."

To ensure that our interpretations of students' responses to these questions accurately reflected students' experiences, we presented our interpretation to students and asked them to comment on it in a constructedresponse question. For example, students who answered "No" to the first question were then asked, "Your response suggests that you did not encounter struggle in organic chemistry II this semester. Please explain why this is or is not an accurate description of your experience." Written responses to these questions were reviewed by two analysts who were in consensus that there were no discrepancies in our interpretation of students' experiences with success or failure in the course.

\section{Constructed-response survey questions}

On the first survey of the 2018 semester, a constructedresponse question followed each version of the mindset scale that asked students to describe why they held these beliefs about intelligence. Similarly, on the second survey, a constructed-response question asked students to describe how their experience in organic chemistry II so far this semester has affected their responses to the mindset scale items. Students' responses to these questions were analyzed using conventional content analysis 
to identify the factors that could be influencing undergraduate students' mindsets (qualitative analysis described further below; survey questions in Additional file 1, Section 1).

\section{Interviews}

We conducted interviews with a subset of participants to gain deeper insight into students' relevant experiences. Constructed responses were used to select $20 \mathrm{stu}-$ dents to interview. Interviews were semi-structured, meaning that we used an established outline of questions for every interview, but interviewers were free to vary the order of questions to follow the flow of conversation and to ask spontaneous follow-up questions based on participant responses (Fontana \& Frey, 2000). During the interview, participants were asked about their beliefs about intelligence and experiences that shaped their beliefs about intelligence (interview guide in Additional file 1 , Section 2). Participants were compensated with a $\$ 25$ Amazon gift card for completing the interview, which lasted 45-60 min.

\section{Longitudinal data analysis}

We analyzed students' mindset scale responses over time in several steps. First, we tested for measurement invariance to ensure that scores from the mindset scale could be compared across time points. Next, we used multiple group comparisons to determine whether students' personal characteristics influenced their mindset change throughout the semester. Then, we analyzed the change in growth and fixed mindsets over time and the relationship between mindset and students' perceived academic performance using latent growth models. Finally, we estimated latent growth models using only complete cases to confirm that using full information maximum likelihood to handle missing data did not bias our results. All statistical analyses were conducted in the open-source statistical software $\mathrm{R}$ version 3.6.0 using the package "lavaan" (R Core Team, 2018; Rosseel, 2012). Code for all analyses is available in the supplemental materials.

\section{Measurement invariance}

To our knowledge, the mindset scale was not developed or tested for use in repeated measures as we have done here. Therefore, before conducting any analyses, we first tested for measurement invariance to confirm that the internal structure of the measure is consistent across time points. The results indicate that the factor structure remains consistent across time points, and thus, it is reasonable to compare growth and fixed mindset scores to each other across time points (measurement invariance in Additional file 1, Section 5).

\section{Multiple group comparisons}

We collected data on several variables that we hypothesized may influence change in mindset throughout the semester: gender identity, ethnic/racial identity, and generation in college (i.e., first generation or continuing generation). We conducted multiple group comparisons to determine whether distinguishing between these groups improved model data fit (multiple group comparisons in Additional file 1, Section 6). These analyses indicated that differentiating by racial/ethnic identity, gender identity, or generation status did not improve model fit. This indicates that these personal identities/ characteristics did not significantly influence mindset change throughout the semester for students in our sample, so we did not include these variables in the latent growth models.

\section{Latent growth models}

To characterize how students' mindsets changed throughout the semester and the relationship between students' perceptions of failure and mindset, we estimated a series of latent growth models. Latent growth models are a class of structural equation model that decompose the variance-covariance matrix resulting from repeated measurements into latent intercept and slope factors that quantify initial standing on the variable and change in that variable, respectively (Burant, 2016).

We constructed and compared three nested latent growth models (Preacher, Wichman, MacCallum, \& Briggs, 2008). The first model, the "intercept-only model," assumed that mindset scores did not change over time by excluding a slope variable. The second model, the "slope model," included a linear slope latent variable, which allowed mindset scores to change over time $^{1}$. If the slope model is a better fit to the data than the intercept-only model, that would indicate that mindset scores change throughout the semester (i.e., the amount of change is non-zero). The third model was the "full model," and included "failure perception" as a regressor on mindset scores. If the full model better fit the data than the slope model, this would indicate that there is a relationship between students' failure perception and students' initial mindset and/or change in mindset over the semester.

Failure perception was included in the model as two dummy-coded variables with "continued struggle" as the reference group. We were only able to include data from participants who responded to the last survey, when questions measuring failure perception were administered. Thus, the 216 participants who did not answer the

\footnotetext{
${ }^{1}$ Models with non-linear slopes were tested, but were inadmissible, and descriptive and graphical analysis did not present strong evidence for non-linear change. Thus, our data support a linear slope variable.
} 
failure perception questions on the last survey were excluded from the latent growth models (model $n=659$ ).

Following best practices, we evaluated model fit using multiple metrics $\mathrm{Hu} \&$ Bentler, 1999; SchermellehEngel, Moosbrugger, \& Müller, 2003). We avoided placing too much weight on any one metric because each index has different biases and strengths ( $\mathrm{Hu} \&$ Bentler, 1999; Schermelleh-Engel et al., 2003). For example, some are more sensitive to sample size or complexity of the model, and some are used as an absolute measure of fit while others can only be used to compare nested models. Thus, we evaluated our models holistically based on information from multiple different model fit indices. See Additional file 1, Section 3 for a more detailed discussion of our interpretation of model fit indices and commonly used "rules of thumb."

\section{Complete case analyses}

Of the 659 participants included in the latent growth models, only about $60 \%$ completed all four surveys (399 for growth mindset, 421 for fixed mindset). We used full information maximum likelihood (FIML) in the latent growth models to handle missing data. FIML is a common approach for fitting structural models with missing data, but requires that data are missing at random with respect to the outcome variable (Enders, 2010). For example, data missing due to attrition from the study that is related to the outcome of interest (in this case, mindset) would pose a problem. We believe that our data are missing at random because we only included data from students who responded to questions measuring failure perception, which were on the final survey of each semester. Thus, students who stopped participating in the study (e.g., due to withdrawing from the course) are not included in the analyses. In other words, attrition is not an issue in this dataset because only participants who responded to the last survey were included in the models. The only missing data were from intermediate time points, and there is no reason to believe that skipping intermediate surveys should be related to mindset.

To check that using FIML did not substantially impact our analyses and results, we also estimated all latent growth models with only complete cases (i.e., participants who responded to all four surveys). Using only complete cases did not change the results, the full model was still the best fit model for both growth and fixed mindset and the magnitudes and directions of all parameter estimates were virtually unchanged (complete case analyses in Additional file 1, Section 7). Therefore, we present results of latent growth models using FIML.

\section{Qualitative content analysis}

Interviews were recorded and transcribed verbatim. Interview transcripts and responses to open-ended questions asking students to explain why they hold their mindset beliefs (survey 1) and how their mindset beliefs have changed this semester (survey 2) were analyzed qualitatively to identify sources of students' mindsets using the software MAX-QDA 12 (VERBI Software, Berlin, Germany). We eliminated from our analysis survey responses that were off topic or failed to answer the question. In particular, many students responded by reiterating their belief without providing a reasoning or source of their belief. Of the 678 total survey responses, we analyzed 281 to identify reported sources of mindset beliefs.

Since there is no existing theory describing factors that influence undergraduate students' mindsets, we adopted a conventional content analysis approach, which involves deriving coding categories directly from the text data, also referred to as "inductive coding" (Hsieh \& Shannon, 2005). We created codes by identifying sections of text (e.g., sentences or paragraphs) in which participants described factors that affected their mindset beliefs and creating a label (i.e., "code") that captures the idea. As new factors emerged, the codebook was iteratively refined. As necessary, codes were combined, split, or refined, and previous sections of text were revisited and re-coded with the new definitions.

Coding was conducted in an iterative process involving five of the authors as qualitative data analysts: one who had prior experience with content analysis (LL) and four undergraduate researchers with no prior experience ( $\mathrm{C}, \mathrm{HH}, \mathrm{HM}$, and $\mathrm{AB}$ ). Analysts conducted initial coding of a set of text (e.g., one interview or 50 survey responses) independently, then met to discuss to consensus and refine the codebook as necessary. When the codebook was modified or refined, previously coded sets were revisited and recoded as necessary. Two analysts (LL and JC) read all content and were involved in all coding meetings in order to establish trustworthiness through increasing credibility and consistency (Lincoln \& Guba, 1985). Additionally, three other analysts $(\mathrm{HH}, \mathrm{HM}$, and $\mathrm{AB}$ ) read, coded, and discussed partially overlapping subsets of the data to further establish aspects of trustworthiness (i.e., establish confirmability by increasing the diversity of perspectives in analysis) and accommodate analysts' time constraints. The entire qualitative content analysis was completed before the final quantitative models were produced. Thus, coders' interpretations of participants' words were not influenced by knowing the results of the models. Interview participants' quotes are presented using pseudonyms and survey respondents' quotes are presented anonymously with light editing for grammar and spelling. 


\section{Results}

We addressed our two research goals with a combination of quantitative and qualitative results.

\section{Undergraduate students tend to shift towards a fixed mindset}

We used our quantitative results to address our first research goal, which was to characterize how undergraduates' mindsets change in a mid-level, challenging STEM course. To determine whether undergraduate students' mindsets changed over the semester, we compared the fit of the intercept-only model (which assumes that mindset scores do not change) to the slope model (which allows for change over time). The intercept-only models for both growth and fixed mindset fit the data poorly according to all fit statistics; that is, none of the fit statistics fell within a range typically considered acceptable. The slope models were a significantly better fit to the data than the intercept-only models, evidenced by the superior model fit statistics and statistically significant chi-square tests (growth $\Delta \chi^{2}=113.97$, fixed $\Delta \chi^{2}$ 90.87; $p$ 's < 0.001). However, the fit of the slope models was only marginally sufficient (Table 2 ).

We examined the slope model parameters to characterize the change in mindset throughout the semester. Students' growth mindsets decreased slightly throughout the semester, as evidenced by the negative slope of the growth mindset model. Conversely, their fixed mindset increased slightly throughout the semester, evidenced by the positive slope in the fixed mindset model. Model parameters can be interpreted on a scale of $1-7$, where 1 represents "strongly disagree," 4 represents "neither agree nor disagree," and 7 represents "strongly agree." The slope for the growth mindset model suggests a weak decrease between each time point $\left(\beta_{1}=-0.07\right.$, standard error $\left.(\mathrm{se})=0.01, p<0.01\right)$ from the students' starting point $\left(\beta_{0}=5.38\right.$, se $=0.04, p<$ $0.01)$. This implies an overall small decrease in agreement with growth mindset $(-0.28$ points on a 7 -point scale of agreement over the semester). Conversely, the slope variable in the fixed mindset model suggests a weak positive change between each time point $\left(\beta_{1}=\right.$ 0.08 , se $=0.01, p<0.01$ ) from students' starting point $\left(\beta_{0}=2.76\right.$, se $\left.=0.05, p<0.01\right)$. This implies an overall small increase in agreement with fixed mindset $(0.32$ points over the semester).

\section{Factors that influence students' mindsets}

We used both our quantitative and qualitative results to address our second research goal to identify and describe factors that could be influencing undergraduate students' mindsets. We used latent growth models to investigate whether and how students' failure perceptions were related to their changes in mindset throughout the semester. We also qualitatively analyzed survey responses and interview transcripts, resulting in six themes related to sources of mindset: five factors that students reported as influencing their mindset beliefs (academic experiences, observing peers, deducing logically, taking societal cues, and formal learning) as well as uncertainty (counter-examples where students expressed uncertainty about what influenced their mindset beliefs).

\section{Students' mindset changes relate to their failure perceptions} Latent growth modeling indicated that students' changes in mindsets related to their failure perceptions, evidenced by the superior fit of the full model, which included the failure perception variables, compared to the slope model, which did not include failure perceptions. For both growth and fixed mindsets, the full models were the best fit to the data according to all seven fit metrics and chi-square test results indicating that the full models were a significantly better fit than the slope models (Table 2). The full models are in the acceptable or good fit range for all model fit indices, except for the RMSEA. However, the RMSEA is biased for models with low degrees of freedom (Kenny, Kaniskan, \& McCoach, 2015). The full models have only 9 degrees of freedom, which is indeed relatively low.

Students who experienced continued struggle started with different mindsets and followed a different trajectory throughout the semester than students who overcame struggle or never struggled (Fig. 1). Students who began the semester with more fixed and less growth mindsets reported continued struggle (Fig. 2). Students who experienced continued struggle started the semester

Table 2 Model fit statistics and chi-square tests comparing three nested latent growth models for growth and fixed mindset

\begin{tabular}{llllllllll}
\hline Construct & Model & CFI & TLI & SRMR & RMSEA & AIC & BIC & $x^{2}\left(\Delta x^{2}\right)$ & $d f(\Delta d f)$ \\
\hline Growth mindset & Intercept & 0.842 & 0.862 & 0.119 & 0.145 & 6149 & 6176 & $237.49(\mathrm{NA})$ & $16(\mathrm{NA})$ \\
& Slope & 0.921 & 0.915 & 0.069 & 0.114 & 6041 & 6081 & $123.53(113.97)$ & $13(3)$ \\
& Full & 0.950 & 0.922 & 0.045 & 0.109 & 6005 & 6022 & $79.23(44.30)$ & $9(4)$ \\
Fixed mindset & Intercept & 0.870 & 0.886 & 0.118 & 0.130 & 6518 & 6545 & $194.79(\mathrm{NA})$ & $16(\mathrm{NA})$ \\
& Slope & 0.934 & 0.929 & 0.073 & 0.103 & 6434 & 6474 & $103.92(90.87)$ & $13(3)$ \\
& Full & 0.967 & 0.949 & 0.047 & 0.087 & 6391 & 6450 & $53.66(50.26)$ & $9(4)$ \\
\hline
\end{tabular}

Note: All $X^{2}$ and $\Delta \mathrm{X}^{2}$ differences are $p<0.001$ 


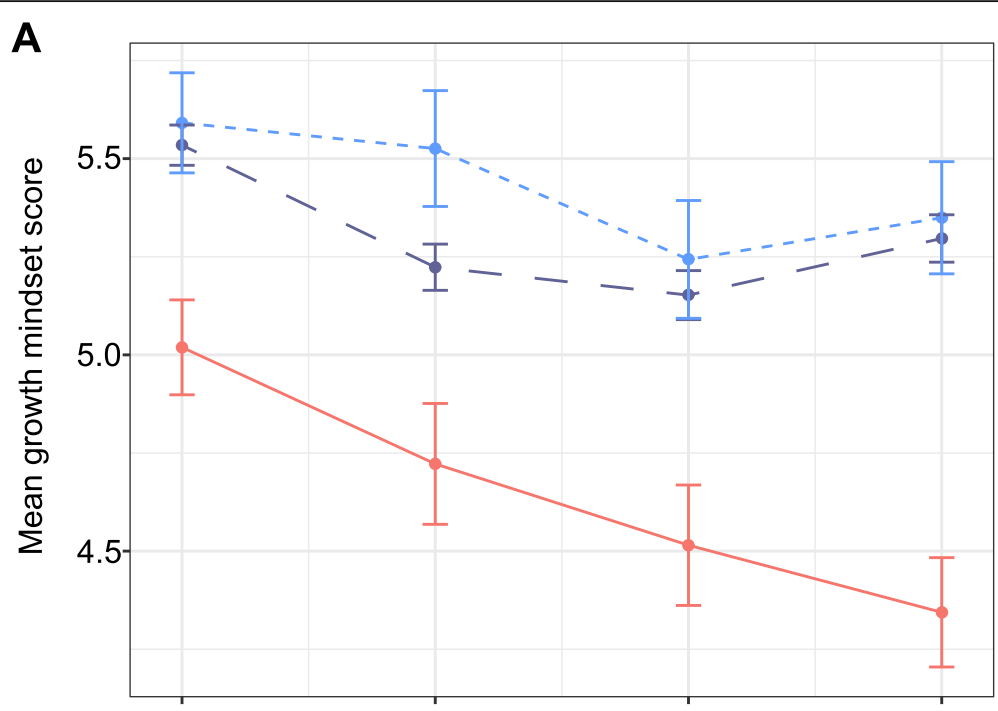

B
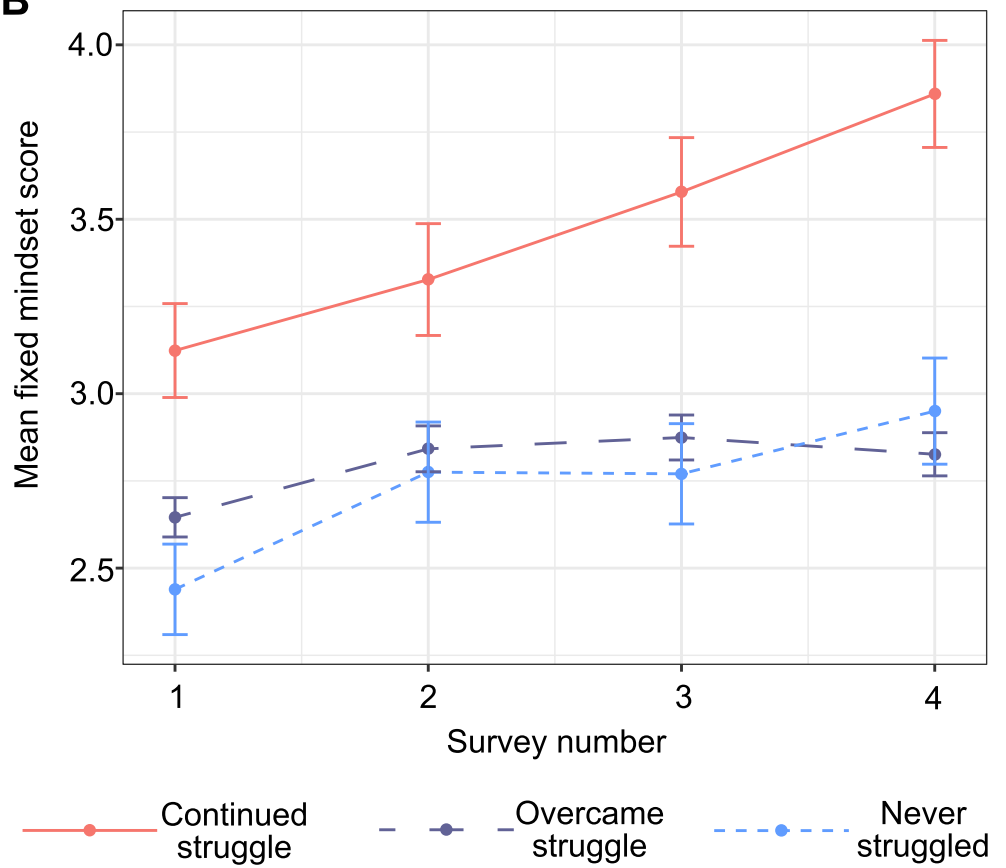

Fig. 1 Average growth mindset scores $(\mathbf{a})$ and fixed mindset scores $(\mathbf{b})$ at each time point by reported failure perception. Error bars are standard error

somewhat agreeing with a growth mindset $\left(\beta_{0}=4.98\right.$, se $=0.10$ ), which was significantly lower than students who overcame struggle $\left(\beta_{0}=5.44, p<0.001\right)$ and students who never struggled $\left(\beta_{0}=5.6, p<0.001\right)$. Conversely, students who experienced continued struggle started the semester somewhat disagreeing with a fixed mindset $\left(\beta_{0}\right.$ $=3.13$, se $=0.11$ ), which was significantly higher (i.e., more agreement) than students who overcame struggle $\left(\beta_{0}=2.71, p=0.001\right)$ and students who never struggled $\left(\beta_{0}=2.54, p<0.001\right)$.

Students' failure perceptions were also related to their mindset change throughout the semester, with students who reported continued struggle experiencing the greatest shift away from a growth mindset and towards a fixed mindset (Figs. 1 and 2). Students who reported continued struggle decreased their growth mindset score by -0.64 points throughout the semester $\left(\beta_{1}=-0.16\right.$, $\mathrm{se}=0.03)$, which was a greater decrease than students who overcame struggle $\left(-0.20\right.$ total; $\beta_{1}=-0.05, p<$ $0.001)$ and students who never struggled ( -0.28 total; $\beta_{1}$ $=-0.07, p=0.016)$. Students who reported continued struggle also experienced the largest increase in their fixed mindset $\left(0.80\right.$ total; $\beta_{1}=0.20$, se $\left.=0.03\right)$. This increase was greater than that experienced by students 

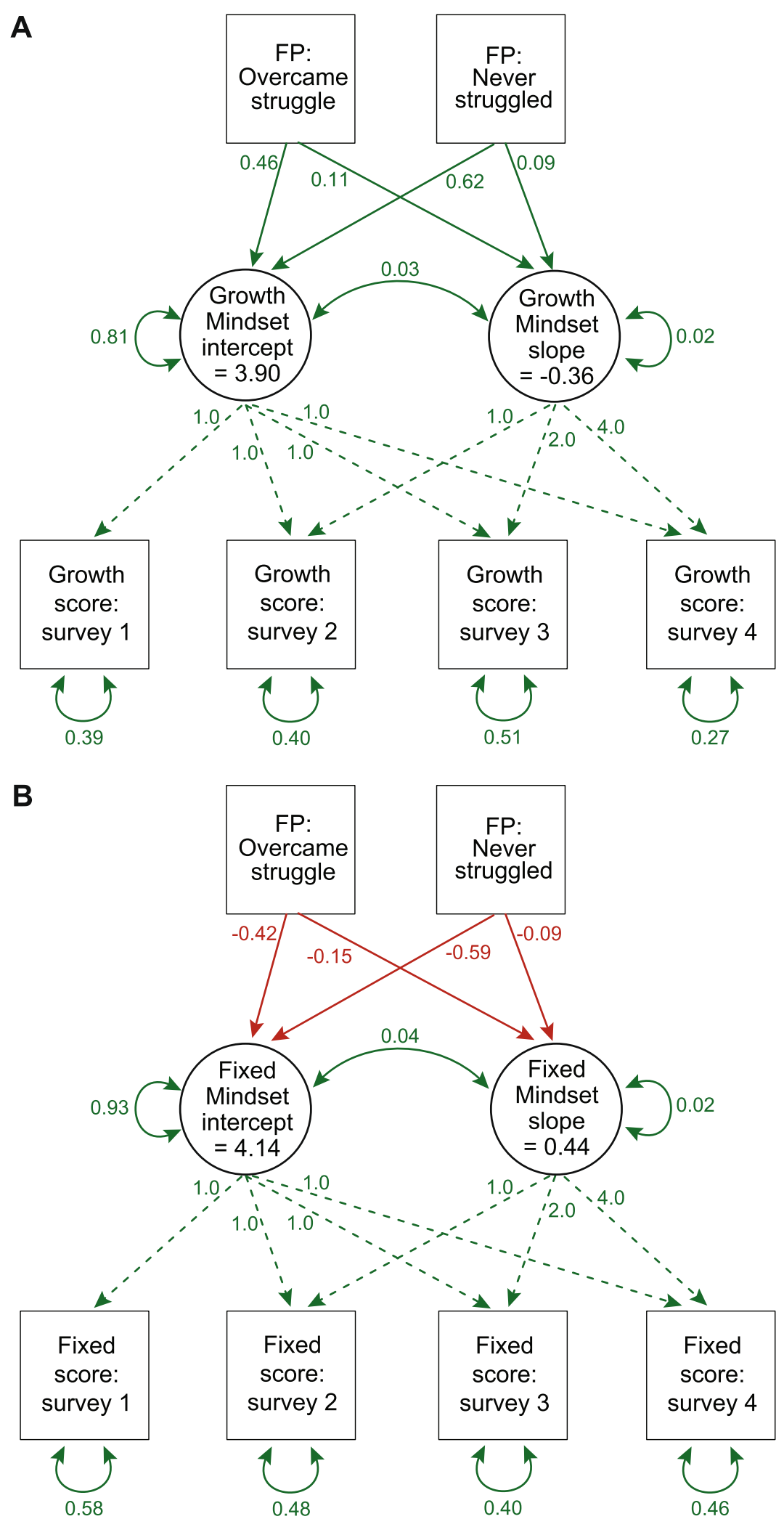

Fig. 2 (See legend on next page.) 
(See figure on previous page.)

Fig. 2 Latent growth model for growth mindset (a) and fixed mindset (b). Circles represent latent variables and squares represent observed variables. Straight solid lines are regression paths. Curved lines are variances and covariances. Dashed lines are latent variable factor loadings. Note: Loadings on the slope variable are 0, 1, 2, and 4 because there was a larger time gap between the 3rd and 4th survey. FP = failure perception, reference group is "continued struggle." All depicted lines are significant at the $p<0.05$ level

who overcame struggle ( 0.20 total; $\left.\beta_{1}=0.05, p<0.001\right)$ and students who never struggled ( 0.44 total; $\beta_{1}=0.11$, $p=0.024)$.

The latent growth models provided evidence of a relationship between students' academic experiences and mindsets. Qualitative analysis corroborated this relationship and further suggested that students' academic experiences may influence their mindsets. Academic experiences were the most commonly discussed of the five factors: 15 of the 20 interview participants and 221 of 281 survey responses described how past academic experiences influenced their mindset beliefs. These responses revealed that students' experiences with academic struggle were particularly influential. When students described struggling in their classes, their mindsets were influenced by whether they overcame their struggle and succeeded or continued to struggle and floundered. Students who reported continued struggle interpreted their struggles as evidence that they were unable to change their intelligence (i.e., fixed mindset). For example, Jade said:

I thought if you had the resources and you worked as hard as you could and you had the help that you needed, you could get to the point that you wanted to be, whether that be like an A or B. ... But then, after O-chem [organic chemistry], I had those resources and I used them and I didn't do as well. So, I thought there might be a threshold to as far as resources could take you. And then at some point, it's really like whether you're genetically capable of connecting concepts or not.

Jade initially had a growth mindset, but she struggled in organic chemistry and failed to achieve her academic goals despite her best efforts. This experience led her to believe that she was not "genetically capable" of mastering organic chemistry, thus shifting her towards a fixed mindset.

In contrast, students who reported overcoming struggle interpreted their success as proof that they could improve their intelligence. For example, one student wrote:

Coming out of high school, I did not have a strong chemistry base. I struggled a bit when I took first semester general chemistry. However, in my second semester of chemistry I felt like I had a better grasp of learning the content and ended up getting an $A$ in the class. So, I do believe it is possible to change your chemistry intelligence level.

Students also discussed how their academic experiences affected their mindsets, even if they did not struggle academically. Students who felt that they had learned as a result of their hard work took this as evidence that they had improved their intelligence. For example, one student wrote:

In O-Chem, I grew greatly in my knowledge of chemistry, as it challenged me to actually understand why certain principles applied and why certain things I learned were happening. I'd say that I would have not learned much of anything if I had not tried and applied myself, so I believe that everyone has the potential if they really care enough to try.

This student described learning a great deal about chemistry without facing any particular struggle. He reasoned that since he was able to learn by dedicating a lot of effort, other students like him should also be able to learn by working hard. Thus, students experiencing intellectual growth, sometimes by overcoming struggle, served as evidence to them that intelligence is improvable. Conversely, when students failed to achieve their goals, they took this as evidence that intelligence is a fixed trait. These results align well with the results from the latent growth models suggesting that students' experiences with success or failure are related to changes in their mindsets.

\section{Students described how observing their peers influenced their mindsets}

Students reported changing their beliefs about the malleability of intelligence when they observed differences among their peers or watched their peers either fail or persevere in the face of struggle. Observing peers was the second most commonly discussed of the five factors: 11 of the 20 interviewees and 57 of 281 survey responses described being influenced by observing others. When they saw their peers fail despite trying their best, they concluded that this failure must be caused by insufficient intelligence. For example, one student wrote:

I have several friends who began in a science major and transferred to different majors after failing to be successful in gen chem [general chemistry] 1. One of 
these friends specifically barely passed gen chem 1, despite spending a significant amount of time studying. However, after switching to a business major she is succeeding tremendously, making $100 \mathrm{~s}$ on accounting tests. This goes to show that though anyone can learn at least a little more chemistry than they knew before, there are many people who simply cannot expand their chemistry knowledge to the depth that chemistry courses require.

This student learned a fixed mindset by observing her friend fail at chemistry and subsequently excel in another area, which she interpreted as evidence that peoples' aptitude for different subjects is fixed. Conversely, students described how observing their peers overcome struggles was evidence that intelligence was malleable. For example, after responding to the mindset scale in a way that was consistent with a growth mindset, one student wrote:

The reason that I hold these beliefs is that my friend was awful at general chemistry and over the summer he changed his attitude on the subject and became more prepared by reviewing over general chemistry material and once the fall semester started, he came to class prepared, read the material, practiced the homework, and was attentive in class, and he came out of Organic Chemistry I with an A-

This student described observing her friend overcome failure and how, as a result, she came to believe it was possible for students like her to improve their intelligence.

Students were also influenced by observing differences in academic performance among their peers. They interpreted these differences as evidence of growth or fixed mindsets depending on the perceived causes and stability of the differences. Students perceived differences that were persistent and stable as evidence of the fixed nature of intelligence, as one student explained:

I have always noticed that people tend to have different levels of intelligence from birth. Although smart people typically work hard in school, I have noticed how other people have a much easier time picking up on things than others with a decent amount of consistency. ... I have never seen anyone that I thought did not have much intelligence vastly improve how much intelligence they have.

This student observed and noted that differences among people were consistent throughout their lives. Notably, this student had not observed any peers improving their intelligence, which suggested to him that it was not possible to do so.

Students viewed the relationship between effort and performance as an indicator of fixed or growth mindset. When students perceived that effort was unrelated to differences in performance, they saw this as evidence of the fixed nature of intelligence. For example, Lydia compared herself to a classmate and said:

I think some students are naturally better at grasping chemistry concepts than others. I feel this way because I competed with a classmate last semester in [organic chemistry I]. [My classmate] always made 20-30 points higher than me on each test and "never studied." He didn't work through practice problems, didn't review his notes, and wouldn't memorize information. On the other hand, I would do all of this and more, studying 30 hours a week in preparation for an exam. This was really challenging for my self-esteem because I didn't understand why I wasn't being rewarded for my effort while [my classmate] was making A's without a sweat. My belief that some students are wired to understand certain concepts has mostly stemmed from experiences such as these.

Although Lydia did not fail, she was frustrated because she noticed a disconnect between effort and performance when she compared herself to her classmate. She thought that, if intelligence was malleable, then more effort should lead to better performance. However, her experience ran counter to her expectations and led her to conclude that she had a fixed level of intelligence that was lower than that of her classmate's.

Conversely, other students observed their peers and concluded that there was a connection between effort and performance. One student wrote:

I was part of an advanced math and science program in high school and I noticed that the kids that were at the top of the program were the ones that paid attention the entire class while everyone else zoned in and out. ... The most important of these [factors affecting performance] is how much an individual is willing to focus on a subject.

This student saw how effort led to success by watching peers who exerted more effort out-perform those who did not pay as much attention in class. He interpreted this difference as evidence that increased effort led to success, reflecting a growth mindset. These results suggest that students can learn their mindset beliefs from observing secondhand experiences of their peers, even if they themselves do not fail or overcome struggles. 


\section{Students reasoned from scientific principles to explain their mindsets}

Some students provided logical arguments as evidence of their growth mindsets. One interviewee and 31 of 281 survey responses used reasoning to support their mindset beliefs. We identified three arguments students used to support their mindsets: blank slate reasoning, reasoning about the nature of science, and reasoning about brain plasticity. Students who used these sorts of reasoning tended to hold a growth mindset; students in our sample who held a fixed mindset rarely provided logical arguments to support them.

Blank slate reasoning is the idea that people are born knowing nothing ("blank slates") and that knowledge develops throughout their lives. Students reasoned that since they are born knowing nothing about chemistry, and increase their chemistry intelligence throughout their education, then their chemistry intelligence must be malleable. For example, one student wrote:

We can grow our knowledge and understanding, so intelligence must be changeable. At one point in time, we all knew nothing about chemistry. So then how could people become chemistry majors or professors if we couldn't change our chemistry knowledge and understanding?

This student reasoned that the existence of chemistry experts supports the growth mindset perspective, because they were not born as experts.

Other students reasoned about intelligence based on the nature of science. Since science is constantly changing and updating, students concluded that intelligence must be able to change as well. One student wrote:

I believe that the basis of science is discovery and learning more than you knew going into it. If no one can truly change the depth of their knowledge on any subject, then what is even the point of attending college and getting a degree? You go to class and learn because it increases your understanding of the topic.

According to this student, science as an enterprise is based on new discoveries and learning, implying that intelligence must also be changeable.

Finally, students also reasoned about the implications of brain plasticity. One student combined his knowledge of brain plasticity with his personal experience recovering from a concussion. He wrote:

I believe that intelligence is something that is malleable. Just as scientists are learning that the brain is actually able to heal itself like other body parts, influenced by proper lifestyle habits (eating, exercising, sleeping), I also believe it's possible to change one's intelligence in the same way. So, I believe that although people are born with certain IQs, IQ can change throughout a person's lifetime. ... I believe this because of my own experience with concussions. My brain was able to repair itself (to what extent, I will find out) after concussions. In the same way, I believe that by taking care of your brain, you can actually change its structure and performance ... So, likewise, one can change his or her IQ.

This student used his knowledge of the brain's capacity to change its physical structure to argue that it must be possible to increase one's intelligence.

Nearly all students who used logic and reasoning to draw conclusions about the nature of intelligence endorsed a growth mindset. However, one student discussed brain plasticity and critical periods as evidence of a fixed mindset for adults. During her interview, Kayla said:

My thought process on it is that because of brain plasticity as a child, you grow up with this huge capability to learn. ... Then you reach a certain age and it becomes more like you either can or you can't learn it. ... By the time you get to a certain age, your brain cannot change that much from plasticity, you're not going to make more neural connections as you could as a child. That's why it's easier to learn languages and stuff [as a child]. So, I think a lot of it has to do with how you were raised and the type of learning you experience as a child that will make way for whether or not you can learn things in the future.

Kayla referenced the fact that young children learn languages more easily than adults as evidence for her view that adults' intelligence is not changeable. Thus, Kayla has a fixed mindset about the intelligence of college-aged students since she believes that intelligence could only be changed by intervention in early childhood. These results suggest that what students learn about some topics indirectly related to intelligence (e.g., the nature of science and brain plasticity) can influence their mindset beliefs, and may ultimately impact their academic success.

\section{Students described how societal cues affected their mindsets}

A couple of students observed that the structure of their school system implied innate differences in intelligence levels (one interviewee and one survey respondent). Alice explained how young students are separated into classes based on their intelligence: 
When you're a kid, people learn to read really quick, or they don't. People get math really easily, they get numbers and everything, or they don't. I feel like you were separated based off your intelligence. ... [My elementary and middle school classes] were all separated not based off your home room, they were based off of your level of intelligence, and it was pretty clear.... I was in the higher English group ... you could see their books were longer, their books were shorter. And the math you were doing, you could completely tell in your homeworks with you and your friends when you were looking at it, like, you're doing so much more work and you learn their math a lot earlier. So, I think I realized that there was definitely a difference in intelligence levels at a young age.

Alice observed as a child that she and her peers were sorted into classes based on intelligence and students at different intelligence levels were treated differently, with more intelligent students being assigned more difficult work. This cued her at a young age to believe that people have different innate levels of intelligence that are permanent throughout a student's life.

Another student observed that IQ testing and standardized testing implied that students have a fixed level of intelligence that is measured through these tests: "IQ and similar testing standards currently in place lay out the idea that intelligence is an inherent trait that is simply something that one possesses." While these sentiments were relatively uncommon, they revealed that students perceived the implicit messages in favor of a fixed mindset from educational practices such as sorting classes based on academic performance and intelligence testing.

\section{Students described how their formal learning influences their mindsets}

Four students discussed learning about IQ and intelligence in their high school advanced placement psychology courses. Interestingly, these four students reported learning very different things about intelligence. For example, George said he was told that intelligence is a fixed trait:

[In] AP psych, and in high school, we did a bunch of intelligence and IQ stuff. And all those thoughts. And I remember it teaching like, "intelligence is like your innate- what you're capable of doing."

Conversely, another student recalled being taught that intelligence is entirely malleable. He wrote,

"I was more-or-less explicitly told in my high school AP Psychology and FCID 3100 (Peer Learning Assistant Pedagogy Seminar) that intelligence is malleable and is the capacity to improve one's amount of learned knowledge and skills."
The other two students remembered learning about intelligence in the context of a "nature vs. nurture" debate; these students held more mixed mindsets. For example, Lily spoke in detail about a report she wrote about "nature vs. nurture" and how it informed how she thought about intelligence:

When I wrote my paper on drug addiction and nature versus nurture, I think I kind of held the same stance that nature does play a very important role in it and how you're inclined to be addicted to things, but nurture, or your environment, is ultimately going to decide if you do. So yeah, I do think it [the malleability of intelligence] varies from person to person. I want to say genetics is more important, but then as soon as I say that, I think that it just varies.

Lily acknowledged the importance of both genetic and environmental aspects, but leaned towards thinking that innate, genetic influences are more important. The varied mindsets of these students highlight how the framing of content in psychology courses can lead students to adopt very different mindsets.

\section{Students were sometimes uncertain about the sources of their beliefs}

A handful of participants (seven of 281 survey responses) explained that they were not sure why they held their growth or fixed mindset beliefs. For example, one student wrote:

"I don't know exactly how these beliefs formed, there wasn't any specific event or lesson throughout my life that caused me to think this way, but this is just how I feel and think about the situation."

These examples demonstrate that students are not necessarily aware of or able to articulate the factors that influence their mindset beliefs.

\section{Limitations}

There are a number of limitations to consider when interpreting these data and drawing conclusions. First, this exploratory study was conducted in a single course at a single institution with relatively low diversity in terms of students' personal characteristics, backgrounds, and experiences. Further, students volunteered to participate, which may lead to bias in the participant pool. We attempted to mitigate this bias by offering incentives for participating (i.e., extra credit for surveys) to maximize response rates. Thus, students in this sample represent a limited portion of the population of undergraduates in the USA (Table 1). These results could be strengthened by replication with a more representative sample of undergraduates. 
Second, recent evidence suggests that the mindset scale does not function reliably when used with undergraduate students (Limeri et al., 2020). Ambiguity of the wording of the items (specifically, the term "intelligence") may increase noise and effectively obscure underlying effects. Thus, if anything, this implies the estimates of effects from our models are underestimates. For example, we did not detect significant influences of race, gender, or generation in college on changes in mindset. In light of measurement problems with the mindset scale, these null results should not be interpreted as evidence that these factors do not influence mindset change. Additionally, we collected data using two versions of the mindset scale: one about "general intelligence" and one about "chemistry intelligence." We elected to only analyze data from the "chemistry intelligence" measure because students' responses to open-ended survey questions and interview comments suggested that they interpreted "general intelligence" in more varied ways than "chemistry intelligence." This may limit the extent to which these conclusions can be generalized to domains beyond chemistry. We elected to use this measure for this study because, despite these limitations, it is currently the best available tool to measure mindset. The first and second authors are working on developing a new mindset measure to reliably measure the mindset of undergraduate students. Future research with an improved measure should be conducted to replicate these results.

Third, like many longitudinal studies, our study is limited by missing data. This issue is mitigated by the fact that participants had to respond to the final survey in order to be included in the model, eliminating effects of differential attrition. However, this limits the extent to which findings from this study can be generalized. That is, the quantitative results do not include students who dropped out from the study and it is unclear how well these results can generalize to the undergraduate chemistry student population. To address these concerns, we also conducted analyses with complete cases only, which yielded nearly identical results.

Finally, we presented five factors that students reported as influencing their mindset beliefs. However, drawing conclusions about causality from qualitative data is controversial (Maxwell, 2004). Our study design does not allow us to test causal influences. Additionally, students reported these factors retrospectively, and thus, these results are prone to recall bias as well as other cognitive biases. Therefore, readers should keep in mind that these are factors that students retrospectively reported as influencing their mindset beliefs. Further studies should be done to more directly test causality.

\section{Discussion}

Here we examine how mid-level chemistry undergraduate students' mindsets about chemistry change during a semester and explore the factors that influence the observed changes. We found that students tended to shift slightly towards a fixed mindset and away from a growth mindset and that the trajectory of their mindset change was related to their experiences with academic struggle. This corroborates and extends prior work demonstrating that introductory STEM students' mindsets tend to shift towards fixed beliefs during their first year of college (e.g., Dai \& Cromley, 2014; Flanigan et al., 2017). We also identified five factors that students described as shaping their mindsets: academic experiences, observing peers, deducing logically, taking societal cues, and formal learning. These results build on prior work, which has explored sources of mindsets focusing primarily on younger students (Dweck, 1999; Kamins \& Dweck, 1999; Mueller \& Dweck, 1998). These studies indicate that the nature of praise communication from adults influences children's mindsets. Similarly, some of our participants spoke about their mindset beliefs being influenced by what they learned in their psychology classes, suggesting that how authority figures (e.g., parents and teachers) talk about intelligence is still influential. However, participants in our study primarily spoke about how their own experiences and observations affected their mindset beliefs (e.g., their own academic experiences, observing peers' experiences). Thus, it is possible that the factors that influence students' mindset beliefs shift over time, from predominantly messages from authority figures to reliance on personal experiences and observations. Altogether, our results indicate that mindset should not be considered a stable trait in undergraduate students, but rather a dynamic trait that is influenced by students' current and prior experiences in their studies and other contextual factors.

Our results suggesting that students' mindsets were influenced by their academic experiences have implications for mindset theory. Extensive prior research has documented that students' mindsets influence their academic performance (e.g., Dweck \& Leggett, 1988; Yeager et al., 2019). However, the possibility that students' performance also influences their mindsets has rarely been considered. One study found evidence for this effect in Greek middle school students (Gonida et al., 2006), but we are unaware of any prior evidence of this relationship in undergraduate students. Our longitudinal data provide evidence of a positive feedback loop: mindsets influence students' perceptions of their academic performance and students reported that their academic performance influences their mindsets (Fig. 3). Although we measured students' perceptions of their academic performance and not their actual performance, our data 


\section{Mindset beliefs influence academic performance}

- Prior research: many studies including Dweck \& Leggett, 1988; Yeager et al., 2019

- Latent growth model results: students who struggled began with more fixed mindsets
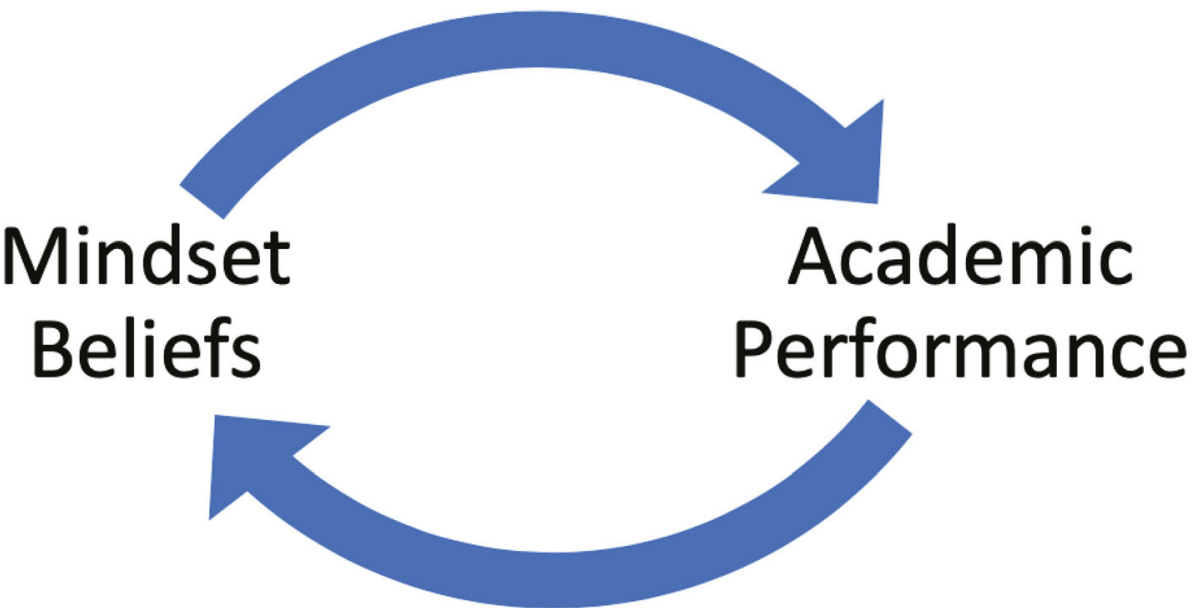

\section{Academic performance influences mindset beliefs}

- Prior research: Gonida et al., 2006

- Latent growth model results: perceived failure associated with greater shift to fixed mindset

- Survey and interviews results: students described how failure led to fixed mindset \& success led to growth mindset

Fig. 3 Mindset beliefs and academic performance each influence each other and thus constitute a positive feedback loop. There is evidence in the literature and from the results reported here for both parts of this feedback loop

corroborate extensive prior research that mindsets influence students' academic performance. Students who began the semester with a lower growth mindset and a higher fixed mindset were more likely to report experiencing continued struggle throughout the semester.

Our results also provide novel evidence that students' academic experiences affected the trajectory of their mindset change throughout the semester. This relationship was supported by both our quantitative data (i.e., the significant effect of failure perception on the slope) and qualitative data (i.e., students' interviews and written survey responses). The fit of our latent growth models indicated that students who experienced continued struggle had the strongest shifts away from a growth mindset and towards a fixed mindset. Students who experienced some degree of success in the course, either by never encountering struggle or overcoming struggle, experienced smaller shifts in their mindsets. It is not possible to infer causality from the latent growth models alone because change in mindset and academic experiences occurred simultaneously throughout the semester. Our qualitative results corroborated this relationship and further suggested that, at least from the students' perspective, past academic experiences may influence students' mindset beliefs (Maxwell, 2004). Students in our sample who overcame struggle described their experience as evidence that their intelligence improved and thus shifted toward a growth mindset. Conversely, students who continued to struggle described their experience as evidence that they were not capable of improving their intelligence, and thus shifted toward a fixed mindset. Collectively, these results suggest that 
mindset and performance could reciprocally affect each other. This implies that undergraduate students' early experiences with struggle may have the potential to shape their mindset beliefs, which in turn influence their future academic performance. However, while the data presented here suggest that students' academic experiences affect their mindset beliefs, we are unable to definitely test causality with this study design. Rather, we pose the recursive model (Fig. 3) as a hypothesis that should be tested in future studies.

These results have implications for the design of and research on mindset interventions. There is evidence that nearly half of mindset interventions reported in the literature are insufficiently persuasive and thus fail to produce positive student outcomes (Sisk et al., 2018). The five factors we identified that students reported as influencing their mindsets could potentially inform the design of mindset interventions. The first factor is their prior academic experiences with struggle, failure, and success. Mindset interventions may influence students by asking them to reflect on past times when they have learned or overcome a struggle, reminding them that they are capable of doing so. In this way, interventions may tap into and capitalize on the positive feedback loop between mindset beliefs and academic performance. Additionally, this finding could inform the timing of mindset interventions, which is an important element of designing effective interventions (Yeager \& Walton, 2011). If academic experiences trigger a positive feedback loop between academic experiences and mindset beliefs, then intervening at an early stage may be critical to achieving positive student outcomes. Helping students overcome early struggles may help them adopt a stronger growth mindset, making it more likely they will continue to overcome future struggles and further affirm their growth mindset.

The second factor we identified is observing their peers deal with struggle or noting differences among their peers. Students described being influenced by seeing their friends or other students overcome struggles and recognizing that it was possible for themselves as well. Mindset interventions could capitalize on this social element by having students or near-peers share stories about how they have overcome academic struggles by dedicating more effort, seeking help, or changing their study strategy. This may inspire students to believe that they are also capable of overcoming their own struggles. Additionally, students interpreted differences among their peers as evidence of a growth or a fixed mindset, depending on whether they viewed these differences as stable or related to effort. Thus, another possible design for mindset interventions would be to influence how students interpret the differences they observe among their peers, encouraging them to view differences as related to effort or study strategy rather than innate differences in intelligence.
The third factor influencing students' mindsets is reasoning from scientific principles. Mindset interventions may be more influential if they integrate the everevolving nature of science and information about brain plasticity in adulthood. Some mindset interventions already convey their message by teaching students about brain plasticity (e.g., Yeager \& Dweck, 2012). However, these interventions are typically targeted at younger students. It may be necessary to craft these messages to an older student audience who may have a more sophisticated knowledge of brain plasticity. For example, in our study, one student cited the lower plasticity of adults' brains compared to children's as evidence for a fixed mindset. Thus, it may be necessary to identify and address specific ideas that undergraduates have about brain plasticity in mindset interventions targeted at the undergraduate level. It may be fruitful to test interventions that teach about the neurobiology of learning, emphasizing the physical changes that take place in the brain (Owens \& Tanner, 2017).

The last two factors influencing students' mindsets are ideas about intelligence communicated by societal cues (e.g., IQ testing implies a fixed intelligence) and psychology courses (e.g., intelligence is entirely genetically controlled). These results indicate that what students learn about intelligence in their psychology courses may have important implications for how they view themselves and their academic performance. Intelligence is a common topic in psychology courses, yet a recent study analyzed the content of 29 of the most popular introductory psychology textbooks and discovered that $79 \%$ of them contained inaccurate statements or logical fallacies about intelligence (Warne, Astle, \& Hill, 2018). Thus, mindset interventions may be more convincing if they directly address some common misconceptions about intelligence and IQ.

Future research should evaluate whether these suggested modifications could improve the persuasiveness and effectiveness of mindset interventions. This assessment could involve "manipulation checks" where students' mindsets are measured before and after the intervention to ensure that the intervention actually shifted students towards a growth mindset. These brief checks could be used to compare different intervention designs and reveal critical intervention elements.

\section{Conclusions}

We found that students tend to shift towards a stronger fixed mindset and a weaker growth mindset during a challenging, upper-level STEM course and that this trend is particularly strong for students who struggle in the course. We identified five factors that influence undergraduates' mindsets: academic experiences, observing peers, deducing logically, taking societal cues, and formal 
learning. Prior research has focused on mindset's influence on academic performance. Our results support this effect and further suggest that academic performance influences students' mindsets, constituting a positive feedback loop. The factors influencing mindset we identified could be leveraged by researchers and practitioners to design and evaluate more persuasive mindset interventions.

\section{Supplementary information}

Supplementary information accompanies this paper at https://doi.org/10. 1186/s40594-020-00227-2.

Additional file 1. Supplemental files

Additional file 2. $R$ code files for all analyses.

\section{Abbreviations}

AIC: Akaike's Information Criteria; BIC: Bayesian Information Criteria; CFI: Comparative Fit Index; FIML: Full Information Maximum Likelihood; RMSEA: Root Mean Square Error of Approximation; SE: Standard Error; SRMR: Standard Root Mean Square Residual; STEM: Science, Technology, Engineering, and Math; TLI: Tucker-Lewis Index

\section{Acknowledgements}

We are grateful to the course instructors for facilitating this study and our participants for sharing their perspectives and time. We thank two anonymous reviewers for their comments on a previous version of this manuscript.

\section{Authors' contributions}

LBL contributed to conceptualizing and designing the study, collecting the data (administering surveys and conducting interviews), analyzing the qualitative and quantitative data, and writing the manuscript. NTC contributed to analyzing the quantitative data. JC contributed to designing the study, collecting the data (administering surveys and conducting interviews), and analyzing the qualitative data. HGH contributed to designing the study, collecting the data (administering surveys and conducting interviews), and analyzing the qualitative data. HRM contributed to analyzing the qualitative and quantitative data. AB contributed to analyzing the qualitative data. ELD contributed to conceptualizing and designing the study. The authors read and approved the final manuscript.

\section{Funding}

This material is based upon work supported in part by the National Science Foundation under Grant Number 1659423 and Grant Number 1937684. Any opinions, findings, and conclusions or recommendations expressed in this paper are those of the authors and do not necessarily reflect the views of the National Science Foundation. Additional funding for this work came from the Center for Integrated Research on Teaching and Learning at the University of Georgia. No funding agencies had any role in the design of this study.

\section{Availability of data and materials}

The quantitative data generated and analyzed during this study are included in this published article and its supplementary information files. The qualitative data (i.e., constructed survey responses and interview transcripts) are available from the corresponding author on reasonable request.

\section{Competing interests}

The authors declare that they have no competing interests.

\section{Author details}

'Department of Biochemistry \& Molecular Biology, University of Georgia, B206.2 Life Sciences Building, 30602 Athens, GA, USA. ²Department of Psychology, University of Georgia, 30602 Athens, GA, USA. ${ }^{3}$ Department of Biology, Agnes Scott College, 30030 Decatur, GA, USA. ${ }^{4}$ Department of Biology, University of North Carolina at Chapel Hill, Chapel Hill, NC 27599, USA.
Received: 5 February 2020 Accepted: 29 May 2020

Published online: 08 July 2020

\section{References}

Aronson, J., Fried, C. B., \& Good, C. (2002). Reducing the effects of stereotype threat on African American college students by shaping theories of intelligence. Journal of Experimental Social Psychology, 38(2), 113-125. https:// doi.org/10.1006/jesp.2001.1491.

Burant, C. J. (2016). Latent growth curve models: Tracking changes over time. The International Journal of Aging and Human Development, 82(4), 336-350. https://doi.org/10.1177/0091415016641692.

Cook, D. A., Castillo, R. M., Gas, B., \& Artino, A. R. (2017). Measuring achievement goal motivation, mindsets and cognitive load: Validation of three instruments' scores. Medical Education, 51(10), 1061-1074. https://doi.org/10. 1111/medu.13405.

R Core Team. (2018). R: A language and environment for statistical computing. $R$ Foundation for Statistical Computing. https://www.R-project.org/

Dai, T., \& Cromley, J. G. (2014). Changes in implicit theories of ability in biology and dropout from STEM majors: A latent growth curve approach. Contemporary Educational Psychology, 39(3), 233-247. https://doi.org/10.1016/ j.cedpsych.2014.06.003.

DeSimone, J. A., Harms, P. D., \& DeSimone, A. J. (2015). Best practice recommendations for data screening. Journal of Organizational Behavior, 36(2), 171-181. https://doi.org/10.1002/job.1962.

Dweck, C. S. (1999). Self-theories: Their role in motivation, personality, and development. New York: Psychology Press.

Dweck, C. S., \& Leggett, E. L. (1988). A social-cognitive approach to motivation and personality. Psychological Review, 95(2), 256-273.

Enders, C. K. (2010). Applied Missing Data Analysis. New York: Guilford Press.

Flanigan, A. E., Peteranetz, M. S., Shell, D. F., \& Soh, L.-K. (2017). Implicit intelligence beliefs of computer science students: Exploring change across the semester. Contemporary Educational Psychology, 48, 179-196. https://doi. org/10.1016/j.cedpsych.2016.10.003.

Fontana, A., \& Frey, J.H. (2000). The interview: From structured questions to negotiated text. In N. K. Denzin \& Y. S. Lincoln (Eds.), Handbook of Qualitative Research (2nd ed., pp. 645-672). Thousand Oaks: Sage Publications.

Gonida, E., Kiosseoglou, G., \& Leondari, A. (2006). Implicit theories of intelligence, perceived academic competence, and school achievement: Testing alternative models. The American Journal of Psychology, 119(2), 223-238. https://doi.org/10.2307/20445336.

Gunderson, E. A., Hamdan, N., Sorhagen, N. S., \& D'Esterre, A. P. (2017). Who needs innate ability to succeed in math and literacy? Academic-domainspecific theories of intelligence about peers versus adults. Developmental Psychology, 53(6), 1188-1205. https://doi.org/10.1037/dev0000282.

Heine, S. J., Kitayama, S., Lehman, D. R., Takata, T., Ide, E., Leung, C., \& Matsumoto, $H$. (2001). Divergent consequences of success and failure in Japan and North America: An investigation of self-improving motivations and malleable selves. Journal of Personality and Social Psychology, 81(4), 599-615. https://doi.org/10. 1037/0022-3514.81.4.599.

Hoyert, M., \& O'Dell, C. (2008). Goal orientation and the aftermath of an academic failure. International Journal of Learning, 15(3), 245-251.

Hsieh, H.-F., \& Shannon, S. E. (2005). Three approaches to qualitative content analysis. Qualitative Health Research, 15(9), 1277-1288. https://doi.org/10. $1177 / 1049732305276687$.

Hu, L., \& Bentler, P. M. (1999). Cutoff criteria for fit indexes in covariance structure analysis: Conventional criteria versus new alternatives. Structural Equation Modeling: A Multidisciplinary Journal, 6(1), 1-55. https://doi.org/10.1080/ 10705519909540118.

Kamins, M. L., \& Dweck, C. S. (1999). Person versus process praise and criticism: Implications for contingent self-worth and coping. Developmental Psychology, 35(3), 835-847. https://doi.org/10.1037/0012-1649.35.3.835.

Kenny, D. A., Kaniskan, B., \& McCoach, D. B. (2015). The performance of RMSEA in models with small degrees of freedom. Sociological Methods \& Research, 44(3), 486-507. https://doi.org/10.1177/0049124114543236.

Kinlaw, C. R., \& Kurtz-Costes, B. (2003). The development of children's beliefs about intelligence. Developmental Review, 23(2), 125-161. https://doi.org/10. 1016/50273-2297(03)00010-8.

Limeri, L. B., Choe, J., Harper, H. G., Martin, H. R., Benton, A., \& Dolan, E. L. (2020) Knowledge or abilities? How undergraduates define intelligence. CBE-Life Sciences Education, 19(1), ar5. https://doi.org/10.1187/cbe.19-09-0169. 
Lincoln, Y. S., \& Guba, E. G. (1985). Establishing trustworthiness. In Naturalistic Inquiry (pp. 289-327). Thousand Oaks: Sage Publications.

Maxwell, J. A. (2004). Using qualitative methods for causal explanation. Field Methods, 16(3), 243-264. https://doi.org/10.1177/1525822X04266831.

Mueller, C. M., \& Dweck, C. S. (1998). Praise for intelligence can undermine children's motivation and performance. Journal of Personality and Social Psychology, 75(1), 33-52. https://doi.org/10.1037/0022-3514.75.1.33.

Orosz, G., Péter-Szarka, S., Bőthe, B., Tóth-Király, l., \& Berger, R. (2017). How not to do a mindset intervention: Learning from a mindset intervention among students with good grades. Frontiers in Psychology, 8, 1-11. https://doi.org/10 3389/fpsyg.2017.00311.

Owens, M. T., \& Tanner, K. D. (2017). Teaching as brain changing: Exploring connections between neuroscience and innovative teaching. CBE Life Sciences Education, 16(2), fe2. https://doi.org/10.1187/cbe.17-01-0005.

Pomerantz, E. M., \& Saxon, J. L. (2001). Conceptions of ability as stable and selfevaluative processes: A longitudinal examination. Child Development, 72(1), 152-173. https://doi.org/10.1111/1467-8624.00271.

Preacher, K. J., Wichman, A. L., MacCallum, R. C., \& Briggs, N. E. (2008). Latent Growth Curve Modeling. SAGE.

Robins, R. W., \& Pals, J. L. (2002). Implicit self-theories in the academic domain: Implications for goal orientation, attributions, affect, and self-esteem change. Self and Identity, 1(4), 313-336. https://doi.org/10.1080/15298860290106805.

Rosseel, Y. (2012). lavaan: An R package for structural equation modeling. Journal of Statistical Software, 48(2), 1-36.

Schermelleh-Engel, K., Moosbrugger, H., \& Müller, H. (2003). Evaluating the fit of structural equation models: Tests of significance and descriptive goodnessof-fit measures. Methods of Psychological Research, 8(2), 23-74.

Scott, M. J., \& Ghinea, G. (2014). On the domain-specificity of mindsets: The relationship between aptitude beliefs and programming practice. IEEE Transactions on Education, 57(3), 169-174. https://doi.org/10.1109/TE.2013. 2288700 .

Shively, R. L., \& Ryan, C. S. (2013). Longitudinal changes in college math students' implicit theories of intelligence. Social Psychology of Education, 16(2), 241256. https://doi.org/10.1007/s11218-012-9208-0.

Sisk, V. F., Burgoyne, A. P., Sun, J., Butler, J. L., \& Macnamara, B. N. (2018). To what extent and under which circumstances are growth mind-sets important to academic achievement? Two meta-analyses. Psychological Science, 29(4), 549571. https://doi.org/10.1177/0956797617739704.

Smiley, P. A., Buttitta, K. V., Chung, S. Y., Dubon, V. X., \& Chang, L. K. (2016). Mediation models of implicit theories and achievement goals predict planning and withdrawal after failure. Motivation and Emotion, 40(6), 878894. https://doi.org/10.1007/s11031-016-9575-5.

Warfa, A.-R. M. (2016). Mixed-methods design in biology education research: Approach and uses. CBE Life Sciences Education, 15(4), rm5. https://doi.org/10. 1187/cbe.16-01-0022

Warne, R. T., Astle, M. C., \& Hill, J. C. (2018). What do undergraduates learn about human intelligence? An analysis of introductory psychology textbooks. Archives of Scientific Psychology, 6(1), 32-50. https://doi.org/10.1037/ $\operatorname{arc0000038.~}$

Yeager, D. S., \& Dweck, C. S. (2012). Mindsets that promote resilience: When students believe that personal characteristics can be developed. Educational Psychologist, 47(4), 302-314. https://doi.org/10.1080/00461520.2012.722805.

Yeager, D. S., Hanselman, P., Walton, G. M., Murray, J. S., Crosnoe, R., Muller, C., Tipton, E., Schneider, B., Hulleman, C. S., Hinojosa, C. P., Paunesku, D., Romero, C., Flint, K., Roberts, A., Trott, J., lachan, R., Buontempo, J., Yang, S. M., Carvalho, C. M., et al. (2019). A national experiment reveals where a growth mindset improves achievement. Nature, 573, 364-369. https://doi.org/10. 1038/s41586-019-1466-y.

Yeager, D. S., \& Walton, G. M. (2011). Social-psychological interventions in education: They're not magic. Review of Educational Research, 81(2), 267-301.

\section{Publisher's Note}

Springer Nature remains neutral with regard to jurisdictional claims in published maps and institutional affiliations.

\section{Submit your manuscript to a SpringerOpen ${ }^{\circ}$ journal and benefit from:}

- Convenient online submission

- Rigorous peer review

- Open access: articles freely available online

- High visibility within the field

- Retaining the copyright to your article

Submit your next manuscript at $\boldsymbol{\nabla}$ springeropen.com 